\title{
Graphene-Gold Nanoparticle Composite Counter Electrode for Cobalt-electrolyte-based Dye-sensitized Solar Cells
}

\author{
Mohammad Al-Mamun, ${ }^{1}$ Jung-Hyurk Lim, ${ }^{1}$ Yung-Eun Sung, ${ }^{2}$ and Sung-Ryong Kim*1 \\ ${ }^{1}$ Department of Polymer Science and Engineering, Korea National University of Transportation, \\ Chungju 380-702, Korea \\ ${ }^{2}$ School of Chemical and Biological Engineering, Seoul National University, \\ Seoul 151-742, Korea
}

(Received August 8, 2012; CL-120830; E-mail: srkim@ut.ac.kr)

\begin{abstract}
Composites of a few layers of graphene $(\mathrm{G})$ with different loadings of $\mathrm{Au}$ nanoparticles (NPs) were used as counter electrodes for dye-sensitized solar cells. Simple solution coating followed by a post thermal treatment was employed for the preparation of the counter electrodes. The graphene composite electrode with $30 \mathrm{nM}$ Au NPs showed a $6.55 \%$ higher conversion efficiency $(\eta=1.79 \%)$ and $200 \mathrm{mV}$ higher opencircuit voltage $(0.60 \mathrm{~V})$ than cells fabricated with sputtered $\mathrm{Pt}$ electrodes. The better electrocatalytic activity of the composite electrode was also reflected in the sharp reduction peaks observed in the cyclic voltammogram.
\end{abstract}

Dye-sensitized solar cells (DSSCs) are of great interest owing to their simple fabrication procedure, low cost, and high conversion efficiencies. ${ }^{1,2}$ A typical DSSC consists of a mesoporous semiconducting film coated with a quasi-monolayer of light-harvesting dye molecules, a redox electrolyte, and a catalytic cathode material coated on a transparent conductive oxide (TCO) substrate. $^{3}$ Counter electrodes (CEs) play an important role in transferring electrons from the external circuit back to the electrolyte redox couple and catalyzing the $\mathrm{Co}^{3+}$ reduction at the counter-electrode/electrolyte interface. ${ }^{4,5}$ Conventionally, platinum $(\mathrm{Pt}$ )-coated TCO substrates are used as counter electrodes in DSSCs to achieve sufficient electrochemical conversion on the counter-electrode surface. ${ }^{6}$ It is well known that the corrosive nature of iodine restricts the use of other metals such as silver, gold, etc. as cathode materials in DSSCs. ${ }^{7}$ The development of cobalt-based mediator systems has opened a new era of using non-Pt metals in counter electrodes. ${ }^{8}$ Despite the unique stability and excellent electrochemical properties of $\mathrm{Pt}$, there are some disadvantages such as its scarcity and high cost. Therefore, carbon nanostructures such as carbon nanotubes, graphene, and other carbon derivatives could be effective as replacements for $\mathrm{Pt}$ as cathode materials in DSSCs. ${ }^{9-11}$

In recent years, graphene $(\mathrm{G})$, a novel $2 \mathrm{D}$ material with fascinating properties, has become a promising candidate for several electronics and energy-based applications. ${ }^{12}$ Graphene has been integrated extensively into DSSCs because of its high charge-carrier mobility, high catalytic activity, chemical stability, and high optical transmittance. ${ }^{13}$ Various papers have already reported G-based CEs in DSSCs. However, graphene films alone were found to be insufficient for the proper harnessing of solar energy. ${ }^{14}$ Graphene composites with different types of metal nanoparticles are expected to exhibit better performances than graphene alone. ${ }^{15} \mathrm{G}-\mathrm{Pt}$ nanoparticle (NP) composites have been reported to be promising cathode materials for DSSCs, exhibit- ing even better performances than sputtered Pt and Pt NPs. ${ }^{16} \mathrm{Au}$ NPs have the advantages of a high surface-to-volume ratio, good catalytic properties, size-controllable synthesis, and low cost. ${ }^{17}$ The attachment of Au NPs on graphene could decrease the production costs of DSSCs significantly.

To the best of our knowledge, composites of Au NPs and graphene have not been reported as counter electrodes in DSSCs owing to the corrosive nature of iodine. Au NPs were introduced to graphene, which could provide additional surfaces and catalytic sites for cobalt-electrolyte-based DSSCs. In this study, simple solution coating followed by post thermal annealing was employed for the preparation of G-Au NP composite counter electrodes. Synergistic electrochemical enhancement of the composite CEs was observed, with slightly higher photoconversion efficiencies than sputtered Pt counter electrodes.

$\mathrm{Au}$ NPs were synthesized according to the procedures published elsewhere. ${ }^{18}$ The concentration of 12-nm Au NPs was determined by UV-visible spectroscopic methods, and different concentrations in the range $15-60 \mathrm{nM}$ were used for the preparation of the $\mathrm{G}-\mathrm{Au}$ composites. Graphene oxide (GO) was prepared by Hummer's method, and all other chemicals were used without further purification. The GO-Au NP dispersions were prepared by adding $1 \mathrm{mg} \mathrm{mL}^{-1} \mathrm{GO}$ to an aqueous solution of $\mathrm{Au}$ NPs. The mixture was sonicated for $5 \mathrm{~h}$ to disperse the GO sheets with the Au NPs. The composite solutions were spincoated on oxygen-plasma-treated fluerine doped tin oxide (FTO) glass at $800 \mathrm{rpm}$ for $20 \mathrm{~s}$. Initial heating at $120^{\circ} \mathrm{C}$ for $10 \mathrm{~min}$ was performed to remove any residual water on the film. After the primary heat treatment, the films along with the FTO glass were subjected to thermal annealing under a continuous flow of $70 \mathrm{sccm}$ argon at a heating rate of $20^{\circ} \mathrm{C} \mathrm{min}^{-1}$, then held at $800^{\circ} \mathrm{C}$ for $4 \mathrm{~h}$, and allowed to cool down to room temperature. Cobalt redox couples, i.e., $\mathrm{Co}^{3+/ 2+}$ tris(4,40-di-tert-butyl-2,20bipyridyl) $\left\{\left[\mathrm{Co}\left(t-\mathrm{Bu}_{2} \mathrm{bpy}\right)_{3}\right]^{3+/ 2+}\right\}$, were synthesized according to the procedure reported in a previous paper. ${ }^{19}$ The final electrolyte was composed of $0.22 \mathrm{M}\left[\mathrm{Co}\left(t-\mathrm{Bu}_{2} \mathrm{bpy}\right)_{3}\right]^{3+/ 2+}$, $0.20 \mathrm{M} \mathrm{LiClO}_{4}$ (Aldrich, 99.99\%), 0.20 M 4-tert-butylpyridine (Aldrich, 96\%), and 0.02 $\mathrm{M} \mathrm{NOBF}_{4}$ (Aldrich, 95\%) in acetonitrile. $\mathrm{TiO}_{2}$ (Ti-Nanoxide $\mathrm{D}$, Solaronix SA, film thickness ca. $8 \mu \mathrm{m}$ ) was sensitized by a ruthenium sensitizer (N719, Solaronix SA) and assembled with the predrilled modified counter electrode by using a Surlyn ${ }^{\circledR}$ spacer. Then, a few drops of the cobalt complex electrolyte were injected into the cell. Synthesized Pt NP and sputtered Pt counter electrodes were also prepared for comparison. The Pt-NP-based counter electrodes were prepared by spin coating a $5 \mathrm{mM}$ ethanolic solution of chloroplatinic acid hexahydrate $\left(\mathrm{H}_{2}\left[\mathrm{PtCl}_{6}\right] \cdot \mathrm{H}_{2} \mathrm{O}\right)$ on FTO glass and sintering at $380^{\circ} \mathrm{C}$ for $20 \mathrm{~min}$. Cyclic voltammograms 


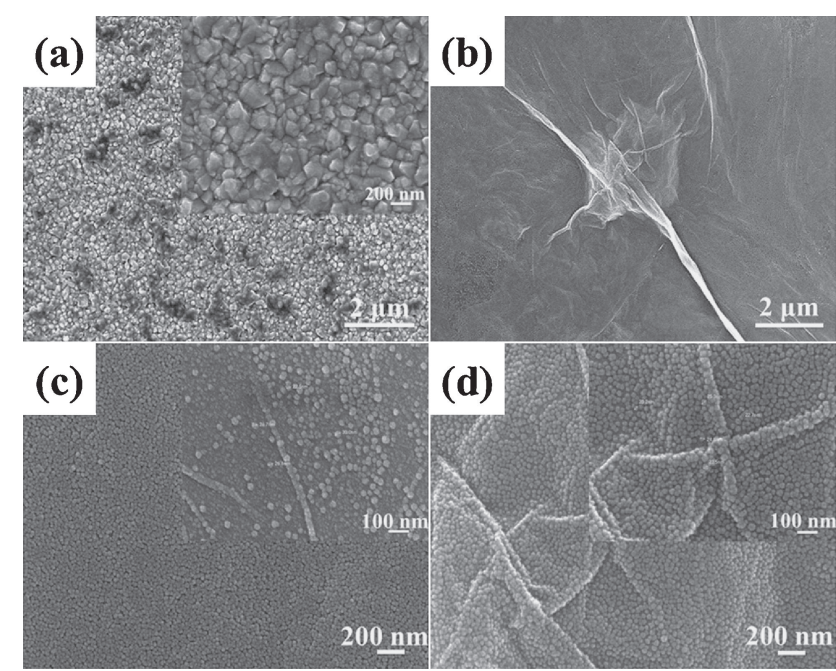

Figure 1. FE-SEM images of (a) bare FTO glass, (b) G-Au NPs (60 nM) composite film, (c) G-Au NPs (30 nM), and (d) G$\mathrm{Au}$ NPs $(60 \mathrm{nM})$ on FTO glass substrate. Inset shows the higher magnification of the respective films.

(CVs) were recorded using an Autolab PGSTAT12 (the Netherlands) in the voltage range -0.40 to $0.80 \mathrm{~V}$ (with respect to a saturated $\mathrm{Ag} / \mathrm{Ag}^{+}$reference electrode) at a scan rate of $100 \mathrm{mV} \mathrm{s}^{-1}$ in a three-electrode configuration. The diluted electrolyte for the $\mathrm{CVs}$ consisted of $2.2 \mathrm{mM} \mathrm{Co}^{3+}$ complex, $0.2 \mathrm{mM} \mathrm{NOBF}_{4}$, and $0.1 \mathrm{M} \mathrm{LiClO}_{4}$ in acetonitrile. A Pt wire was used as the counter electrode. The detailed fabrication and characterization methods are described in the literature. ${ }^{20}$

Figure 1 shows the scanning electron micrographs of bare FTO glass and G-Au NP composite films over FTO glass substrates. The FTO layer was fully covered by the G-Au NP (60 nM) composite film, and the distribution of Au NPs on the G sheet was uniform, as shown in Figure 1b. It should also be mentioned that the degree of aggregation of the Au NPs increased with higher Au NP concentrations. The size of the aggregated Au NPs was found to be ca. $20 \mathrm{~nm}$ for the $30 \mathrm{nM} \mathrm{G}-$ Au NP composite film (Figure 1c), whereas larger aggregated particles (ca. $30-50 \mathrm{~nm}$ ) were observed for the $60 \mathrm{nM} \mathrm{G-Au} \mathrm{NP}$ composite film (Figure 1d). The agglomerated size of Au NPs on the basal plane of graphene was increased with increasing $\mathrm{Au}$ NP concentration.

The optical transmittance spectra of bare FTO glass, sputtered Pt, G, and G-Au NP composite films with different concentrations of $\mathrm{Au}$ NPs are presented in Figure 2a. The G-Au NP composite films showed ca. 3\% lower transmittances than the bare FTO glass. The transparencies of the composite films were shown to be dependent on the Au NP loading amount on the basal plane of the graphene sheets. The G-Au NP (60 nM) composite film showed $74.5 \%$ transmittance; this lower transmittance could be related to the surface plasmonic resonant absorption of Au NPs at $520 \mathrm{~nm}^{21}$ However, all the G-Au NP composite counter electrodes showed better transparencies than the sputtered Pt counter electrode.

The electrochemical behaviors of different types of composite electrodes were investigated through $\mathrm{CV}$ measurements. In Figure $2 b$, a pair of well-defined redox peaks is observed for the
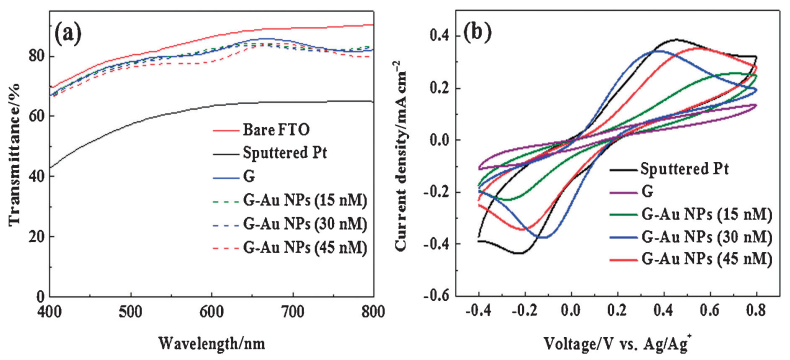

Figure 2. (a) Optical transmittance spectra and (b) cyclic voltammograms of different types of counter electrodes.
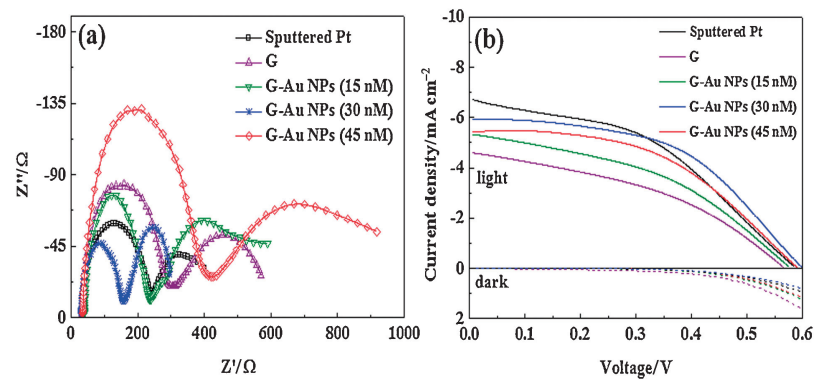

Figure 3. (a) Nyquist plots and (b) $J-V$ characteristic curves of DSSCs based on sputtered Pt, G, and G-Au NPs composite counter electrodes.

sputtered Pt and G-Au NP films, with a reasonable cathodic current for the effective reduction of the cobalt species. Thermally reduced graphene oxide showed a smaller cathodic current density without distinguishable peaks, but the G-NP composite electrodes displayed well-defined redox peaks in the $\mathrm{CVs}$. The magnitude of the cathodic current density of the G-Au $\mathrm{NP}(30 \mathrm{nM})$ composite film was $0.31 \mathrm{~mA} \mathrm{~cm}^{-2}$, which is comparable to the value of $0.30 \mathrm{~mA} \mathrm{~cm}^{-2}$ for sputtered Pt. The agglomerated $\mathrm{Au}$ NP $(30 \mathrm{nM})$ electrode without graphene did not show significant catalytic activity in the CV (not shown). This may be related to the accessibility of the lower electrochemically active surface area during electrochemical conversion. ${ }^{15}$ It is speculated that the presence of $\mathrm{Au}$ NPs in the graphene composite electrode may lower the agglomeration of $\mathrm{Au}$ NPs, increasing the electrochemically active surface and enhancing the electron-transfer process. It is also evident that further increasing the Au NP loading in the graphene composite deteriorated the electrocatalytic property of the electrode. The higher concentration of Au NPs facilitated the formation of bigger clusters, which could decrease the surface-to-volume ratio for effective electrocatalytic conversion. A similar phenomenon was observed for the G-Pt NP composite counter electrode. $^{15}$

Figure $3 \mathrm{a}$ shows the impedance spectra of complete cells fabricated with different types of counter electrodes. The first semicircle in the higher-frequency regime represents the chargetransfer resistance at the counter-electrode surface, whereas the second circle shows the charge-transfer resistance at the working electrode. ${ }^{22}$ The charge-transfer resistance at the counter electrode was decreased significantly for the G-Au NP composite cathodes. All the cells in Figure 3a showed similar series 
Table 1. Photovoltaic performances of DSSCs with different types of counter electrodes

\begin{tabular}{lccccc}
\hline CEs & $\begin{array}{c}\% T \\
(550 \mathrm{~nm})\end{array}$ & $\begin{array}{c}V_{\text {oc }} \\
/ \mathrm{V}\end{array}$ & $\begin{array}{c}J_{\text {sc }} \\
/ \mathrm{mA} \mathrm{cm}^{-2}\end{array}$ & $F F$ & $\begin{array}{c}\eta \\
/ \%\end{array}$ \\
\hline FTO & 83.2 & 0.53 & 1.10 & 0.09 & 0.05 \\
Sputtered Pt & 61.0 & 0.58 & 6.73 & 0.43 & 1.68 \\
Pt NPs & 72.3 & 0.61 & 4.95 & 0.39 & 1.17 \\
G & 80.0 & 0.58 & 4.38 & 0.41 & 1.03 \\
G-Au NPs (15 nM) & 79.9 & 0.58 & 5.32 & 0.42 & 1.28 \\
G-Au NPs (30 nM) & 79.4 & 0.60 & 5.93 & 0.50 & 1.79 \\
G-Au NPs (45 nM) & 77.5 & 0.59 & 5.43 & 0.49 & 1.56 \\
G-Au NPs (60 nM) & 74.5 & 0.58 & 5.52 & 0.45 & 1.43 \\
\hline
\end{tabular}

resistances. The composite films with higher loadings of Au NPs $(>30 \mathrm{nM})$ suffered from higher charge-transfer resistances, which were consistent with the $\mathrm{CV}$ results.

The comparative $J-V$ characteristic curves of the DSSCs using different kinds of cathode materials are presented in Figure $3 \mathrm{~b}$. Table 1 lists the open-circuit voltages $\left(V_{\mathrm{oc}}\right)$, shortcircuit current densities $\left(J_{\mathrm{sc}}\right)$, fill factors $(F F)$, and photoconversion efficiencies $(\eta)$ of the DSSCs. The cells prepared with G-Au NPs $(30 \mathrm{nM})$ showed significantly better performances than graphene alone. The DSSCs prepared with composite counter electrodes also showed a $200 \mathrm{mV}$ increase in opencircuit voltage, with little improvement in their fill factors. The augmented open-circuit potential could be related to the marginal shifting of the reduction peak and the redox potential of the $\mathrm{Co}^{3+} / \mathrm{Co}^{2+}$ system toward the positive side in the case of the composite electrodes. ${ }^{15}$ The cells prepared with the composite counter electrodes showed slightly higher photoconversion efficiencies than the DSSC based on the sputtered Pt counter electrode. It should be noted that relatively lower conversion efficiencies and fill factors were also observed under the same construction of DSSCs. ${ }^{23}$ We believe that the different $J-V$ curves can be attributed to the different electrochemical properties of the counter electrodes. By performing suitable engineering modifications in the working electrode, we would expect to improve the performances of cobalt/G-Au NP dyesensitized solar cells.

$\mathrm{G}-\mathrm{Au} \mathrm{NP}$ composite counter electrodes were investigated as counter electrodes for cobalt-electrolyte-based DSSCs. The electrocatalytic and optical properties of the G-Au NP composite counter electrodes were studied by $\mathrm{CV}$ and light transmission measurements. Synergistic enhancement of the catalytic activity was observed at the Au-NP-decorated graphene counter electrodes. The photoconversion efficiencies (PCEs) of DSSCs based on the G-Au NP composite counter electrodes were shown to be dependent on the Au NP loading. The G-Au NP composite counter electrode revealed a photoconversion efficiency enhanced by $73.7 \%$ compared to that of graphene alone. In addition, the composite counter electrodes exhibited slightly higher photoconversion efficiencies than the sputtered $\mathrm{Pt}$ electrode. This paper reports the effective improvement in PCE by using G-Au NP composite counter electrodes without any corrosion.
This research was supported financially through the Human Resource Training Project for Regional Innovation by the Ministry of Education, Science Technology of Korea. This work was also supported by grants Nos. 2010-0006808 and 20090072876 of the National Research Foundation of Korean Government. This research was supported by the research grant 2012 of Korea National University of Transportation.

\section{References}

1 B. O'Regan, M. Grätzel, Nature 1991, 353, 737.

2 G. Smestad, C. Bignozzi, R. Argazzi, Sol. Energy Mater. Sol. Cells 1994, 32, 259.

3 M. K. Parvez, I. In, J. M. Park, S. H. Lee, S. R. Kim, Sol. Energy Mater. Sol. Cells 2011, 95, 318.

4 G. Zhang, H. Bala, Y. Cheng, D. Shi, X. Lv, Q. Yu, P. Wang, Chem. Commun. 2009, 2198.

5 G. M. Scheuermann, L. Rumi, P. Steurer, W. Bannwarth, R. Mülhaupt, J. Am. Chem. Soc. 2009, 131, 8262.

6 T. N. Murakami, M. Grätzel, Inorg. Chim. Acta 2008, 361, 572.

7 M. Wang, N. Chamberland, L. Breau, J.-E. Moser, R. Humphry-Baker, B. Marsan, S. M. Zakeeruddin, M. Grätzel, Nat. Chem. 2010, 2, 385.

8 A. Yella, H.-W. Lee, H. N. Tsao, C. Yi, A. K. Chandiran, Md. K. Nazeeruddin, E. W.-G. Diau, C.-Y. Yeh, S. M. Zakeeruddin, M. Grätzel, Science 2011, 334, 629.

9 T. Battumur, S. H. Mujawar, Q. T. Truong, S. B. Ambade, D. S. Lee, W. Lee, S.-H. Han, S.-H. Lee, Curr. Appl. Phys. 2012, 12, e49.

10 L. Kavan, J.-H. Yum, M. K. Nazeeruddin, M. Grätzel, ACS Nano 2011, 5, 9171.

11 E. Ramasamy, J. Lee, Carbon 2010, 48, 3715.

12 J. T. Robinson, F. K. Perkins, E. S. Snow, Z. Wei, P. E. Sheehan, Nano Lett. 2008, 8, 3137.

13 K. S. Novoselov, A. K. Geim, S. V. Morozov, D. Jiang, Y. Zhang, S. V. Dubonos, I. V. Grigorieva, A. A. Firsov, Science 2004, 306, 666 .

14 L. Wan, S. Wang, X. Wang, B. Dong, Z. Xu, X. Zhang, B. Yang, S. Peng, J. Wang, C. Xu, Solid State Sci. 2011, 13, 468.

15 R. Bajpai, S. Roy, P. Kumar, P. Bajpai, N. Kulshrestha, J. Rafiee, N. Koratkar, D. S. Misra, ACS Appl. Mater. Interfaces 2011, 3, 3884.

16 V. Tjoa, J. Chua, S. S. Pramana, J. Wei, S. G. Mhaisalkar, N. Mathews, ACS Appl. Mater. Interfaces 2012, 4, 3447.

17 G. Zhu, L. Pan, H. Sun, X. Liu, T. Lv, T. Lu, J. Yang, Z. Sun, ChemPhysChem 2012, 13, 769.

18 K. E. Sapsford, D. Park, E. R. Goldman, E. E. Foos, S. A. Trammell, D. A. Lowy, M. G. Ancona, Langmuir 2008, 24, 10245 .

19 J.-Y. Kim, K. J. Lee, S. H. Kang, J. Shin, Y.-E. Sung, J. Phys. Chem. C 2011, 115, 19979.

20 S.-R. Kim, M. Al-Mamun, Y.-H. Ko, Chem. Phys. Lett. 2012, 538, 77.

21 S. Eustis, M. A. El-Sayed, Chem. Soc. Rev. 2006, 35, 209.

22 Md. K. Parvez, G. M. Yoo, J. H. Kim, M. J. Ko, S. R. Kim, Chem. Phys. Lett. 2010, 495, 69.

23 F. Ghamouss, R. Pitson, F. Odobel, M. Boujtita, S. Caramori, C. A. Bignozzi, Electrochim. Acta 2010, 55, 6517. 